\title{
Diffusion Tensor Imaging in a Patient with Joubert Syndrome
} Joubert Sendromlu Bir Olguda Difüzyon Tensör Görüntüleme

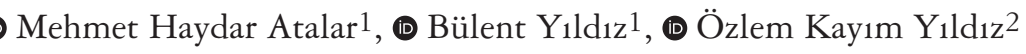 \\ ${ }^{1}$ Cumhuriyet University Faculty of Medicine, Department of Radiology, Sivas, Turkey \\ ${ }^{2}$ Cumhuriyet University Faculty of Medicine, Department of Neurology, Sivas, Turkey
}

Keywords: Diffusion tensor imaging, Joubert syndrome, magnetic resonance imaging

Anahtar Kelimeler: Difüzyon tensör görüntüleme, Joubert sendromu, manyetik rezonans görüntüleme

\section{Dear Editor,}

Joubert syndrome (JS) is a rare hindbrain malformation with autosomal recessive transmission, which was first defined by Marie Joubert in 1969. Its clinical signs include ataxia, hypotonia, abnormal eye movement, nystagmus, hyperpnea-apnea episodes, and mental and motor developmental delay. The absence of the cerebellar vermis creates a midline cleft between the normal cerebellar hemispheres. The combination of cerebellar peduncle hypoplasias is detected in magnetic resonance imaging (MRI) as the molar tooth sign. Diffusion tensor imaging (DTI), which has recently been introduced into routine use, is used for clinical cases where an abnormality exists in the white matter pathways of the brain. It has a significant advantage over conventional MRI techniques for delineating the dislocation of white matter pathways or showing the injured tracts $(1,2,3)$.

A 12-year-old girl presented with clumsiness, developmental delay, hyperactive attacks, and nodding. Her past history was notable for a normal gestational period and birth followed by the absence of any significant health problem in the newborn period. Her family history was also non-remarkable for any abnormalities. Her parents were not related. In neurologic examination, she was found to have rotative nystagmus, hypotonia, and an ataxic gait with a wide base. Her laboratory tests and electroencephalogram were within normal limits. A cerebral MRI was performed, which showed a hypoplastic cerebellar vermis and an enlarged fourth ventricle. Additionally, the superior cerebellar peduncles were thickened, interpeduncular fossa widened, and the pons assumed a molar tooth appearance, which is typical of JS (Figure 1a, 1b).
A DTI performed in addition to MRI showed the absence of a focal red dot normally seen in normal healthy children (Figure 2) at the level of decussation of the superior cerebellar peduncles. It also showed that the vertical orientation of the fibers inside the superior cerebellar peduncles, normally seen in color-coded fractional anisotropy maps in healthy children, was disrupted and showed a more horizontal orientation (Figure 3a, 3b).

Conventional MRI signs are quite well defined in JS. DTI and fiber tractography are novel methods that are capable of showing the direction of fiber tracts. DTI is an imaging method that provides a pure diffusion image by eliminating diffusion's direction-based effects. In DTI, anatomic structures normally not clearly visualized by conventional MRI (particularly white matter pathways) become visible by virtue of their diffusion properties being limited in certain directions. In this way, more information can be obtained about these anatomic structures and surgical procedures and post-treatment follow-up can be conducted on these structures by identifying their anatomic relationship with the pathologic lesions. Color-coded fractional anisotropic maps in JS assess the presence of a focal red dot located anteriorly to the mesencephalon, neighboring the interpeduncular fossa, which represents the reduction of the number of these fiber tracts. The absence of a focal red dot indicates the failure of the decussation of fiber tracts located in the superior cerebellar peduncles and within the laterally located deep cerebellar nuclei $(1,2,3)$.

In conclusion, brain MRI is the gold standard for confirmation of JS. DTI, however, may be useful for better defining diseaserelated abnormal white matter connections.

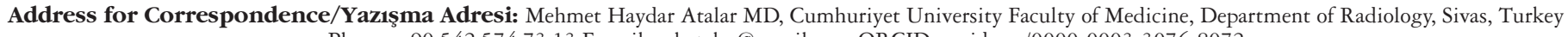
Phone: +90 5425747313 E-mail: mhatalar@gmail.com ORCID: orcid.org/0000-0003-3076-8072

Received/Geliş Tarihi: 05.07.2018 Accepted/Kabul Tarihi: 14.02.2019

${ }^{\oplus}$ Copyright 2019 by Turkish Neurological Society

Turkish Journal of Neurology published by Galenos Publishing House. 

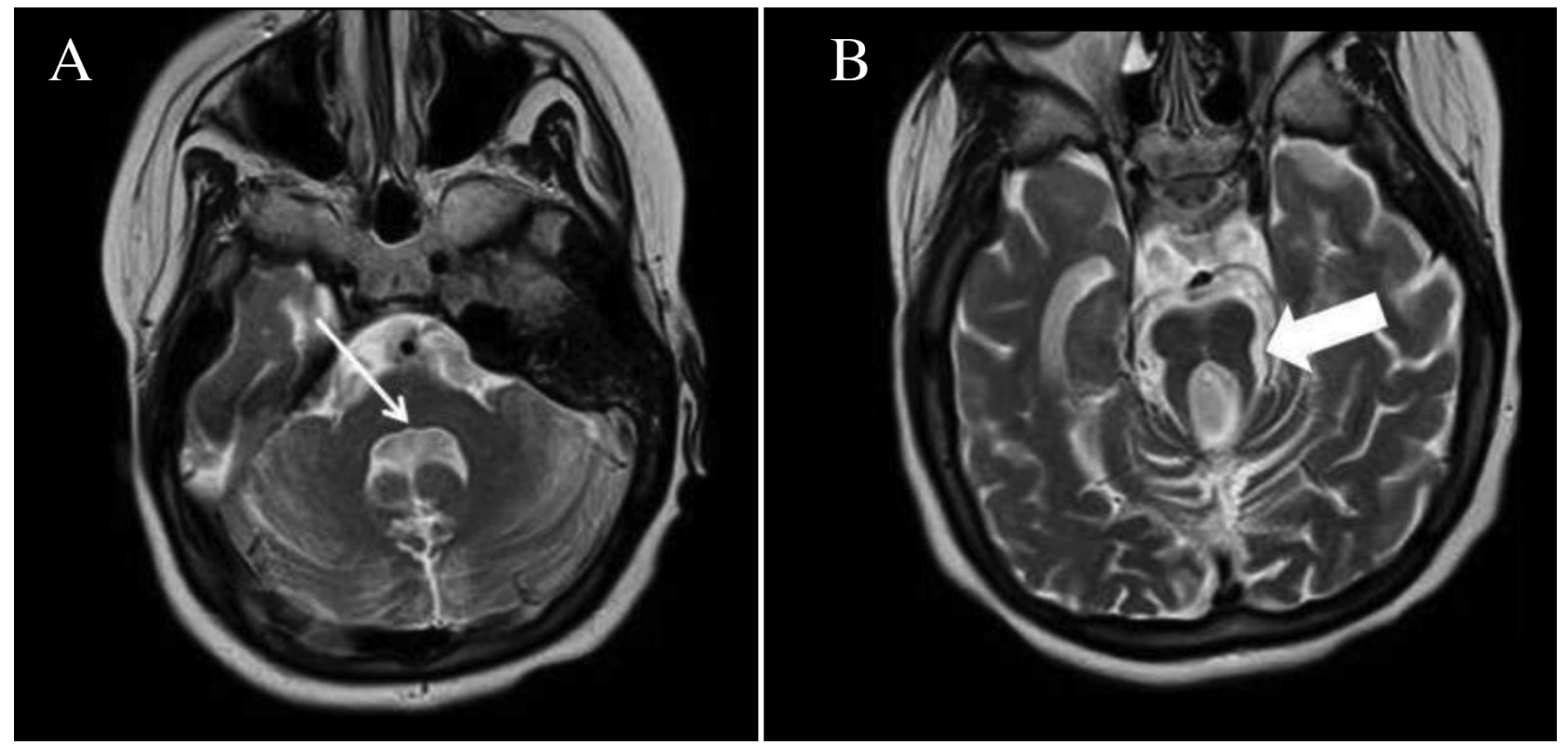

Figure 1. In our patient with JS, axial T2-weighted images demonstrate A) bat wing appearance in the fourth ventricle (thin arrow), and B) the molar tooth sign of the midbrain (thick arrow)

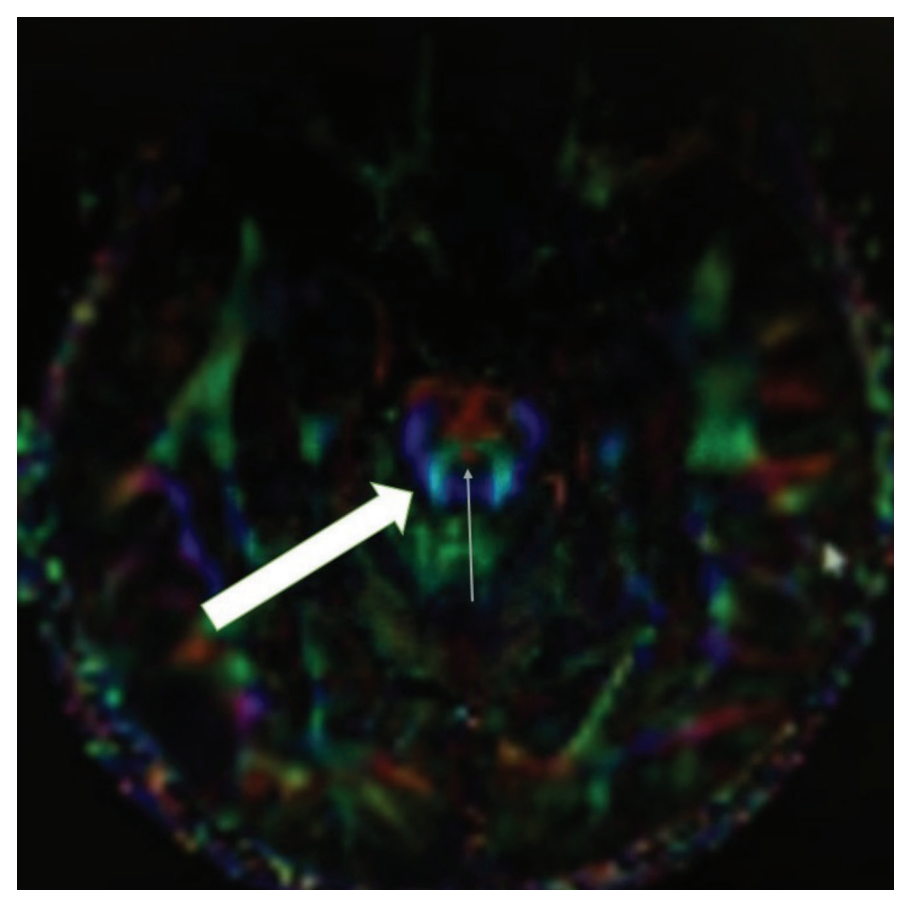

Figure 2. A healthy pediatric subject. Color coded fractional anisotropy map on diffusion tensor imaging shows the decussation of the superior cerebellar peduncles at the level of inferior colliculus of the midbrain as a focal red dot (thin arrow). The thick white arrow shows the vertical orientation of the superior cerebellar peduncles 

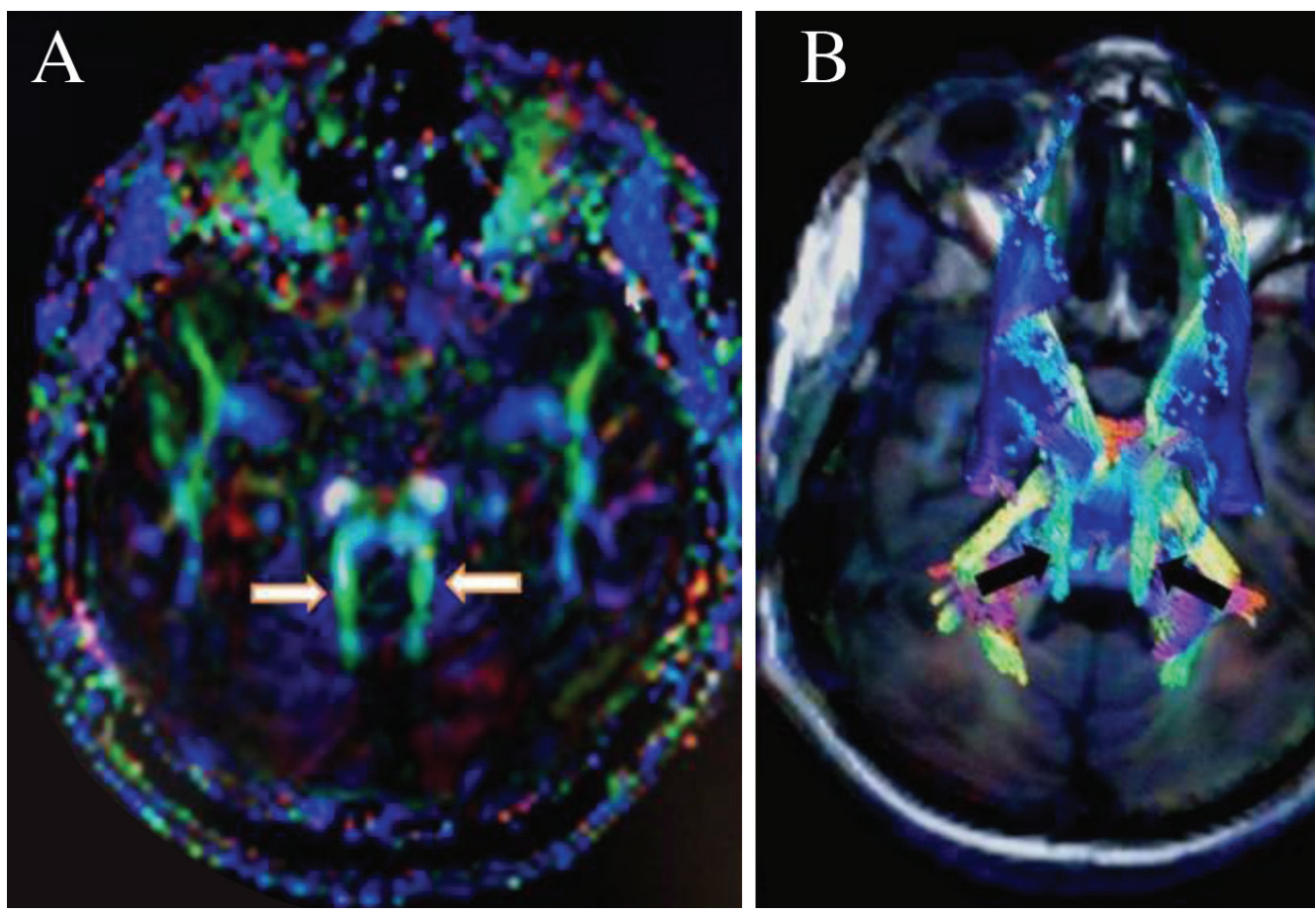

Figure 3. A) On diffusion tensor imaging, the superior cerebellar peduncle fibers had a more horizontal orientation verified by green color coding in color-coded fractional anisotropy maps (white arrows). B) Fiber tractography image shows the horizontal course and thickening of the superior cerebellar peduncles (black arrows) as in color-coded anisotropy maps

\section{Ethics}

Informed Consent: Consent form was filled out by all participants.

Peer-review: Internally peer-reviewed.

\section{Authorship Contributions}

Surgical and Medical Practices: M.H.A, B.Y., Concept: M.H.A., Design: M.H.A., B.Y., Data Collection or Processing: M.H.A., B.Y., Analysis or Interpretation: M.H.A., B.Y., Literature Search: M.H.A., B.Y., Ö.K.Y., Writing: M.H.A., B.Y., Ö.K.Y.

Conflict of Interest: No conflict of interest was declared by the authors.
Financial Disclosure: The authors declared that this study received no financial support.

\section{References}

1. Poretti A, Boltshauser E, Loenneker T, et al. Diffusion tensor imaging in Joubert syndrome. AJNR Am J Neuroradiol 2007;28:1929-1933.

2. Widjaja E, Blaser S, Raybaud C. Diffusion tensor imaging of midline posterior fossa malformations. Pediatr Radiol 2006;36:510-517.

3. Lee SK, Kim DI, Kim J, et al. Diffusion-tensor MR imaging and fiber tractography: a new method of describing aberrant fiber connections in developmental CNS anomalies. Radiographics 2005;25:53-65. 